\title{
Hedonic Olfactory Perception in Depression: Relationship between Self-Evaluation and Autonomic Response
}

\author{
Boriana Atanasova ${ }^{1}$, Philippe Gaillard ${ }^{1,2}$, Frédéric Minier ${ }^{1}$, Catherine Belzung ${ }^{1}$, \\ Wissam El-Hage ${ }^{1,2}$ \\ ${ }^{1}$ INSERM U930 ERL 3106, University François Rabelais, Tours, France \\ ${ }^{2}$ Department of Psychiatry, CHRU, Tours, France \\ Email: atanasova@univ-tours.fr
}

Received July $9^{\text {th }}, 2012$; revised August $13^{\text {th }}, 2012$; accepted September $14^{\text {th }}, 2012$

\begin{abstract}
This study aimed to improve the understanding of hedonic perception in depression using the olfactory modality. We evaluated physiological (heart rate measures) and hedonic responses (subjective rating scale) obtained from 30 unipolar depressed inpatients and 30 healthy controls. The stimuli were two odorants with contrasting hedonic valence, vanillin (pleasant) and butyric acid (foul-smelling), presented at three different concentrations and in nine binary mixtures. Compared to controls, the depressed subjects had significantly increased heart rate response to olfactory stimuli, regardless of valence. These observations were not related to the severity of depression. For both groups, a significant negative correlation was found between the explicit hedonic rating and the implicit instantaneous heart rate measure. Together these pilot findings suggest that unipolar depression is associated with stronger physiological reactions to odorants and a negative bias when processing olfactory stimuli. Further studies are required to confirm these observations in larger groups of depressed subjects.
\end{abstract}

Keywords: Olfaction; Depression; Hedonic Self-Evaluation; Heart Rate Response

\section{Introduction}

Deficient positive affect, or anhedonia, and excessive negative affect (e.g. sadness, guilt) are the two cardinal symptoms of major depressive disorder (MDD) as defined by the DSM-IV (American Psychiatric Association, 1994). In a recent metaanalysis, Bylsma et al. (2008) suggested that depressed individuals had reduced emotional reactivity (i.e. intensity of the emotional response) to both positively and negatively valenced stimuli, with a larger reduction for positive than for negative stimuli as compared to healthy controls. However, the literature on the emotional impairments in MDD is mainly centred on processes supported by visual (pictures, films), verbal (words) or auditory inputs (audiotapes of positive and negative social interactions) (Bylsma et al., 2008). Among the many studies in this field, only a few have explored the emotional and/or hedonic response to olfactory stimuli in depressed individuals, although olfactory processing has been shown to have close links with emotional processing (Ehrlichman \& Bastone, 1992; Zatorre et al., 2000).

\section{Olfactory Hedonic Response and Depression}

Olfactory pleasantness is usually evaluated in depression using an explicit subjective self-rated assessments by different types of scales (line bisection scale anchored on each end with a descriptors, category scale, Likert scale, labeled magnitude scale, self-assessment manikin scale...), with discrepant results. Recent studie has demonstrated that the unpleasant stimulus of butyric acid and the binary mixture of pleasant and unpleasant odours (butyric acid and vanillin) are perceived as significantly more unpleasant by depressed patients than by healthy controls.
No difference between groups was observed for the hedonic evaluation of the pleasant stimulus of vanillin (Atanasova et al., 2010). Earlier, Pause et al. (2001) found that only one odour (citral) out of the ten studied was perceived as significantly more pleasant by depressed patients than by controls. No difference between the hedonic scores of MDD patients and controls was observed by three studies (Thomas et al., 2002; Swiecicki et al., 2009; Clepce et al., 2010). Other studies have found that MDD patients over-evaluate the pleasantness of odorants compared to controls (Lombion-Pouthier et al., 2006; Cumming et al., 2011).

All these results were obtained using self-reported subjective evaluations of odour pleasantness. Overall, they suggest that MDD patients' response to olfactory stimuli is heightened or remains unaffected. This is not in line with expected results based on the observation that depressed people usually experience emotional cues less positively than controls and that their ability to experience pleasantness is frequently impaired (anhedonia). The subjective hedonic rating requires the person to give a cognitive estimation of his/her hedonic perception, which may be impaired in depression. Thus, in order to decrease the risk of cognitive bias in odour hedonic evaluation, a simultaneous objective measurement is needed.

Another possible explanation of the inconsistent findings of the studies mentioned above is that some calculated the hedonic scores by taking all odours irrespective of their hedonic valence, and/or only pleasant stimuli were used (Lombion-Pouthier et al., 2006; Clepce et al., 2010). Differences in methodological approaches, the inclusion of depression subtypes (e.g. unipolar, bipolar MDD), and differences in medication could also account for the inconsistencies. 


\section{Objective Evaluation of the Olfactory Hedonic Response}

Indeed, the hedonic and/or emotional response to olfactory stimuli can be evaluated also through implicit objective measures such as the behavioural analysis (e.g. analysis of facial expressivity), the peripheral physiological reactivity evaluation (e.g. skin resistance, skin blood flow, skin temperature, instantaneous heart rate, etc.) and the central reactivity evaluation (e.g. event-related potentials, neuroimaging metrics). To our knowledge, only one study has used an objective measure (eventrelated potential analysis) to investigate the emotional response to odour in depression (Pause et al., 2003). Furthermore, no research has studied the physiological reactivity to odour in depression, while it has been demonstrated that variations in electrodermal (skin conductance, skin resistance), thermovascular (skin blood flow) and cardiorespiratory (instantaneous heart rate) responses could be modulated by odour pleasantness (Alaoui-Ismailli et al., 1997a, 1997b; Vernet-Maury et al., 1999; Bensafi et al., 2002a). For instance, it has been shown that decreases in instantaneous HR variation are associated with pleasant odours, while increases in HR variation are associated with unpleasant odours.

In an effort to remedy some of the shortcomings mentioned above, two aspects were investigated in the present pilot study. First, the olfactory response was studied using two different evaluations: a subjective hedonic rating scale and an objective measurement of instantaneous heart rate variation (HR). We hypothesized that the depressed patients would perceive the pleasant stimuli as less pleasant than controls and the unpleasant stimuli as more unpleasant than controls (hedonic aspect) using implicit objective method.

Secondly, the consistency between the explicit self-reported hedonic response and the implicit instantaneous HR response was investigated. We hypothesized that the relationship between both measures will be better for healthy controls compared to patients.

\section{Materials and Methods}

\section{Participants}

We recruited 30 depressed inpatients with a current DSM-IV diagnosis of major unipolar depression and 30 healthy controls matched for age and gender. The severity of the depression was evaluated using the Montgomery-Asberg Depression Rating Scale (MADRS) (Montgomery and Asberg, 1979). Ten patients had moderate depression (MADRS scores between 24 and 34) and 20 had severe depression (MADRS > 34). The inpatients were assessed 6.8 days on average $(\mathrm{SD}=6.3)$ after admission to hospital (Department of Psychiatry, Tours Hospital). The DSM-IV axis I psychiatric co-morbidities were assessed by a clinician using the French version of the Mini International Neuropsychiatric Interview (MINI 5.0) (Duburcq et al., 1999). The clinical interviews were carried out by a clinician. On the day of the investigation, all patients were treated with antidepressants. Patients were excluded if they were not able to collaborate or have a verbal conversation due to the severity of depression. The controls were healthy volunteers with no history of mental illness (Table 1). They were recruited by wordof-mouth from families of staff members and from the local community.

All the participants had given prior written consent and were
Table 1.

Clinical description of the participants.

\begin{tabular}{lcc}
\hline & $\begin{array}{c}\text { Depressed patients } \\
(\mathrm{n}=30)\end{array}$ & $\begin{array}{c}\text { Control subjects } \\
(\mathrm{n}=30)\end{array}$ \\
\hline Female/male ratio & $12 / 18$ & $12 / 18$ \\
Age, years (SD) & $34.6(11.1)$ & $33.4(9.9)$ \\
Smoker, female/male ratio & $5 / 13$ & $4 / 5$ \\
Depression: & & - \\
MADRS, score (SD) & $36.3(6.3)$ & $2.0(2.1)$ \\
Duration of current episode. & $6.7(5.2)$ & - \\
months (SD) & $2.1(1.8)$ & - \\
Number of previous episodes (SD) & & - \\
MINI 5.0: & 30 & - \\
MDD, current episode & 11 & - \\
Suicidal risk, last month & 3 & - \\
PTSD, last month & & \\
Other disorders & & \\
\hline
\end{tabular}

MDD: major depressive disorder; PTSD: post-traumatic stress disorder; ${ }^{*}$ (Hypo)Mania. Panic disorder. Obsessive compulsive disorder. Alcohol and cannabis abuse (last 12 months). Psychotic disorder. Eating disorders (last 3 months). Generalized anxiety disorder.

fully informed of the experimental protocol. All subjects were informed that they were free to discontinue testing at any time. They were instructed not to smoke for at least $30-40 \mathrm{~min}$ before the study. Participants were excluded if they had any prior history of brain damage, neurological disorders, current substance abuse, any respiratory infection-induced olfactory loss, odour allergy, current cold, any other medical condition liable to impair olfactory ability (e.g. epilepsy, nasal polyps, etc.), or anosmia to the odorants to be used.

\section{Odour Stimuli}

The stimuli used in the present study were the same as those used previously (Atanasova et al., 2010): vanillin (V) (pleasant odour) and butyric acid (B) (unpleasant odour) supplied by Fisher Scientific (Sigma, France). They were presented at three different supra-threshold concentration levels $(\mathrm{V} 1=60, \mathrm{~V} 2=$ $600, \mathrm{~V} 3=6000 \mathrm{mg} / \mathrm{l}$, and B1 $=.03, \mathrm{~B} 2=.16, \mathrm{~B} 3=.8 \mathrm{mg} / \mathrm{l})$ and in nine possible combinations (binary mixtures). It has been demonstrated that the quality descriptor of some odorants (their respective hedonic valence) could change according to their intensity (Moskowitz et al., 1976). For this reason, three different concentration levels of both odorants were used. However, during the experiment, no individual reported any change of the odour quality descriptor of the three different concentration levels of the two odorants.

Three stimuli chosen at random (one pleasant: V3, one unpleasant: B1, and one binary mixture: B1V2) were presented twice in order to study the test-retest reliability of the subjects' responses. Only three stimuli were duplicated in order to avoid olfactory fatigue and saturation. The odorants were diluted with distilled water (the two compounds were soluble in this solvent at the studied concentrations). The solutions were poured into $60 \mathrm{ml}$ brown glass flasks ( $10 \mathrm{ml}$ per flask) coded with a random, three-digit number. 


\section{Experimental Procedure}

The experimental session lasted approximately one hour. The presentation order of the eighteen stimuli was balanced and was identical for all the subjects in order to compare the results of both groups. Prior to the measures, subjects were informed verbally about the procedure. Firstly, the HR was recorded. The subject was seated comfortably at a table in a quiet room. Each flask containing the odour was opened and placed in front of the subject. The subject was instructed to hold the flask approximately $1-2 \mathrm{~cm}$ from his/her nostrils with the electrodefree hand and smell the odour for 1 to 2 seconds. This task had to be carried out without any other movement or overt response. The subject then placed the flask on the table and the experimenter closed the bottle and presented the next one. The intertrial interval was $2 \mathrm{~min}$, which is the standard period used in experiments recording autonomic parameters (Vernet-Maury et al., 1999; Bensafi et al., 2002a). It also avoids olfactory adaptation and fatigue. All these tasks and parameters were supervised and monitore by the experimenter. Instantaneous HR variation was evaluated using a monitoring electrode placed on the forefinger of the non-dominant hand. The measurements were carried out using the Care ORD-049 monitor (CARE, Bobigny, France). The time is displayed in seconds and the HR in beats per minute (range: 40 to $199 \mathrm{bpm}$ ). HR was measured continuously throughout the session. The HR score of each subject and for each stimulus was calculated by subtracting the mean rate for the $3 \mathrm{~s}$ preceding flask presentation from that for the $8 \mathrm{~s}$ after odour stimulation as described previously (Bensafi et al., 2002a; 2002b). After the HR variation measurements, the subject smelled each flask again and evaluated the pleasantness of the odour using a linear scale labeled at each end (highly unpleasant/highly pleasant), resulting in a hedonic subjective score ranging from 0 to $10(\mathrm{~cm})$. Prior to measurement session, there was a short practice trial to familiarize the subjects with the tasks.

\section{Data Analysis}

The two-tailed paired Student test was used to study the testretest reliability of the subjects' HR and hedonic responses.

HR measurements and hedonic self-evaluations of both groups were computed separately with an analysis of variance with 2 factors: stimulus (15 stimuli: B1, B2, B3, V1, V2, V3, B1V1, B1V2, B1V3, B2V1, B2V2, B2V3, B3V1, B3V2, B3V3) and group (depressed subjects and healthy controls) and one their interaction (group $\times$ stimulus). As significant effects of stimulus, group and group $\times$ stimulus interaction were found, a two-by-two comparison between groups for each stimulus was carried out using Tukey test.

Levene's test for the homogeneity of variances revealed unequal variance for some variables. Parametric analyses have nevertheless been applied in the present study, since the ANOVA is relatively robust against violations of equal variances if the sample size is relatively high (more than 10) and groups are of the same size (Box, 1954). Both conditions applied to our data.

Pearson's correlations were used to assess the correlation between self-reported hedonic responses and HR measurements for each group. Pearson's correlation coefficient was also calculated to study the relationship between the severity of depression (MADRS score) and the HR scores on the one hand and the severity of depression and the hedonic score on the other hand of each pleasant and unpleasant stimulus.

The collected data were analysed using the SigmaStat ${ }^{\circledR} 3.5$ software. A probability value of $p \leq .05$ was considered as statistically significant.

\section{Results}

Firstly, analysis of test-retest reliability of the subjects' responses showed that both groups responded consistently to the three studied stimuli (V3, B1 and B1V2), with both methods (two-tailed paired Student test, $\mathrm{df}=29, p>.05$ ) (Table 2).

\section{HR Measurements}

The HR response results revealed a significant effect of stimulus $(\mathrm{F}(14,870)=52.78, p<.001)$ and group $(\mathrm{F}(1,870)=$ $203.33, p<.001)$. With regard to the group $\times$ stimulus interaction, the results showed a difference between the HR responses of patients and controls according to the stimulus $(\mathrm{F}(14,870)=$ $2.91, p<.001)$. Comparing HR responses of patients and controls (two-by-two comparison between groups for each stimulus) revealed that for all odorant stimuli except one (B2), the mean values of MDD patients were significantly higher than those of healthy subjects $(p<.05)$ (Table 3).

\section{Hedonic Self-Evaluation}

The analysis of variance indicated a significant effect of stimulus $(\mathrm{F}(14,870)=61.91, p<.001)$, group $(\mathrm{F}(1,870)=53.13$, $p<.001)$ and group $\times$ stimulus interaction $(\mathrm{F}(14,870)=2.60$, $p<.001)$. Comparison of the hedonic responses of patients and controls showed that eight stimuli were perceived as significantly less pleasant by MDD patients (two unpleasant stimuli and six binary mixtures). No between-group difference was observed for any pleasant stimuli and for three binary mixtures $(p>.05)$ (Table 3).

\section{Correlation Analysis}

The patients' MADRS scores were not correlated with HR responses for any pleasant stimuli $(\mathrm{V} 1: \mathrm{r}=.03, \mathrm{NS} ; \mathrm{V} 2: \mathrm{r}=-.19$, NS; V3: $r=.26$, NS; $n=30$ ), or any unpleasant stimuli (B1: $r$ $=.03$, NS; B2: $\mathrm{r}=-.04$, NS; B3: $\mathrm{r}=-.06$, NS; $\mathrm{n}=30$ ). There was no relationship between the hedonic scores of each unmixed odorant and the depression scores (V1: $\mathrm{r}=-.16, \mathrm{NS}$; V2: $\mathrm{r}=.22, \mathrm{NS} ; \mathrm{V} 3: \mathrm{r}=.14, \mathrm{NS} ; \mathrm{B} 1: \mathrm{r}=-.25, \mathrm{NS} ; \mathrm{B} 2: \mathrm{r}=-.29$, NS; B3: $r=-.15$, NS; $n=30$ ).

The relationship between hedonic responses and HR responses were studied for each group. The results revealed a significant negative correlation between these two parameters for patients $(\mathrm{r}=-0.86, p<.001, \mathrm{n}=15)$ and controls $(\mathrm{r}=-.79$, $p<.001, \mathrm{n}=15)$ (Figure 1).

\section{Discussion}

The general aim of the present study was to gain a better understanding of hedonic perception in depression using the olfactory modality. This involved two main objectives. The first one was to compare the olfactory response of MDD patients and healthy subjects obtained by subjective hedonic self-evaluation and objective HR measurements. The second was to study the relationship between these two responses to olfactory stimuli for both groups. 
Table 2.

Mean (SD) of heart rate variation score and hedonic response in depressed patients and healthy controls. R1: first repetition; R2: second repetition; V: vanillin; B: butyric acid ( $p$-value: two-tailed paired student test).

\begin{tabular}{|c|c|c|c|c|c|c|c|c|c|c|c|c|}
\hline \multirow{3}{*}{ Stimulus } & \multicolumn{6}{|c|}{ Depressed subjects } & \multicolumn{6}{|c|}{ Healthy subjects } \\
\hline & \multicolumn{3}{|c|}{ Mean heart rate variation } & \multicolumn{3}{|c|}{ Mean hedonic score } & \multicolumn{3}{|c|}{ Mean heart rate variation } & \multicolumn{3}{|c|}{ Mean hedonic score } \\
\hline & $\mathrm{R} 1$ & R2 & $p$ & R1 & R2 & $p$ & $\mathrm{R} 1$ & $\mathrm{R} 2$ & $p$ & $\mathrm{R} 1$ & $\mathrm{R} 2$ & $p$ \\
\hline 1B & $\begin{array}{c}7.2 \\
(1.7)\end{array}$ & $\begin{array}{c}6.9 \\
(1.9)\end{array}$ & .43 & $\begin{array}{c}1.7 \\
(1.1)\end{array}$ & $\begin{array}{c}1.8 \\
(1.4)\end{array}$ & .67 & $\begin{array}{c}5.8 \\
(2.3)\end{array}$ & $\begin{array}{c}5.1 \\
(2.9)\end{array}$ & .12 & $\begin{array}{c}2.6 \\
(1.6)\end{array}$ & $\begin{array}{c}3.0 \\
(1.4)\end{array}$ & .19 \\
\hline $3 \mathrm{~V}$ & $\begin{array}{c}1.4 \\
(2.1)\end{array}$ & $\begin{array}{c}.8 \\
(1.3)\end{array}$ & .13 & $\begin{array}{c}7.2 \\
(2.2)\end{array}$ & $\begin{array}{c}7.0 \\
(2.1)\end{array}$ & .35 & $\begin{array}{l}-2.5 \\
(2.2)\end{array}$ & $\begin{array}{l}-2.0 \\
(1.8)\end{array}$ & .14 & $\begin{array}{c}7.1 \\
(1.9)\end{array}$ & $\begin{array}{c}7.3 \\
(2.3)\end{array}$ & .67 \\
\hline 2V1B & $\begin{array}{c}2.9 \\
(2.2)\end{array}$ & $\begin{array}{c}2.9 \\
(1.8)\end{array}$ & .97 & $\begin{array}{c}4.1 \\
(2.6)\end{array}$ & $\begin{array}{c}4.3 \\
(2.3)\end{array}$ & .40 & $\begin{array}{c}.3 \\
(2.4)\end{array}$ & $\begin{array}{c}.7 \\
(2.3)\end{array}$ & .49 & $\begin{array}{c}5.2 \\
(1.1)\end{array}$ & $\begin{array}{c}5.3 \\
(1.5)\end{array}$ & .80 \\
\hline
\end{tabular}

Table 3.

Mean (SD) heart rate variation and hedonic score to each olfactory stimulus in depressed patients and healthy controls. V: vanillin; B: butyric acid ( $p$-value: two-by-two comparison between groups for each stimulus using Tukey test).

\begin{tabular}{|c|c|c|c|c|c|c|}
\hline \multirow{2}{*}{ Stimulus } & \multicolumn{3}{|c|}{ Mean heart rate variation } & \multicolumn{3}{|c|}{ Mean hedonic score } \\
\hline & Depressed subjects & Healthy subjects & $p$ & Depressed subjects & Healthy subjects & $p$ \\
\hline B1 & $7.22(1.75)$ & $5.76(2.29)$ & .045 & $1.67(1.07)$ & $2.62(1.56)$ & .050 \\
\hline B2 & $6.90(1.68)$ & $7.27(2.60)$ & .610 & $1.26(1.03)$ & $2.48(2.12)$ & .012 \\
\hline B3 & $8.81(1.91)$ & $7.11(3.00)$ & .001 & $0.81(.90)$ & $1.42(1.20)$ & .205 \\
\hline V1 & $.84(1.21)$ & $-1.30(2.18)$ & .020 & $5.50(2.72)$ & $4.91(2.21)$ & .225 \\
\hline V2 & $.85(1.64)$ & $-2.53(1.97)$ & $<.001$ & $7.38(1.90)$ & $7.09(1.94)$ & .779 \\
\hline V3 & $1.35(2.07)$ & $-2.50(2.24)$ & $<.001$ & $7.21(2.18)$ & $7.52(2.02)$ & .805 \\
\hline B1V1 & $2.82(2.73)$ & $.54(2.03)$ & .002 & $3.64(2.57)$ & $4.54(1.34)$ & .065 \\
\hline B1V2 & $2.87(2.18)$ & $.33(2.40)$ & $<.001$ & $4.10(2.57)$ & $5.20(1.08)$ & .024 \\
\hline B1V3 & $2.02(1.57)$ & $-.08(2.35)$ & .004 & $5.12(2.00)$ & $5.79(2.02)$ & .166 \\
\hline B2V1 & $3.37(2.56)$ & $.84(1.83)$ & $<.001$ & $2.47(1.89)$ & $4.10(1.35)$ & $<.001$ \\
\hline B2V2 & $3.45(3.01)$ & $.79(2.59)$ & $<.001$ & $2.35(1.92)$ & $4.46(1.48)$ & $<.001$ \\
\hline $\mathrm{B} 2 \mathrm{~V} 3$ & $3.40(2.55)$ & $.35(1.81)$ & $<.001$ & $3.54(2.38)$ & $5.89(2.16)$ & $<.001$ \\
\hline B3V1 & $3.70(2.10)$ & $.31(2.07)$ & $<.001$ & $1.52(1.80)$ & $2.75(1.90)$ & .011 \\
\hline B3V2 & $4.13(2.31)$ & $.50(1.81)$ & $<.001$ & $1.72(1.77)$ & $2.80(1.51)$ & .026 \\
\hline B3V3 & $4.30(2.38)$ & $.69(2.18)$ & $<.001$ & $2.51(2.44)$ & $2.95(1.58)$ & .370 \\
\hline
\end{tabular}

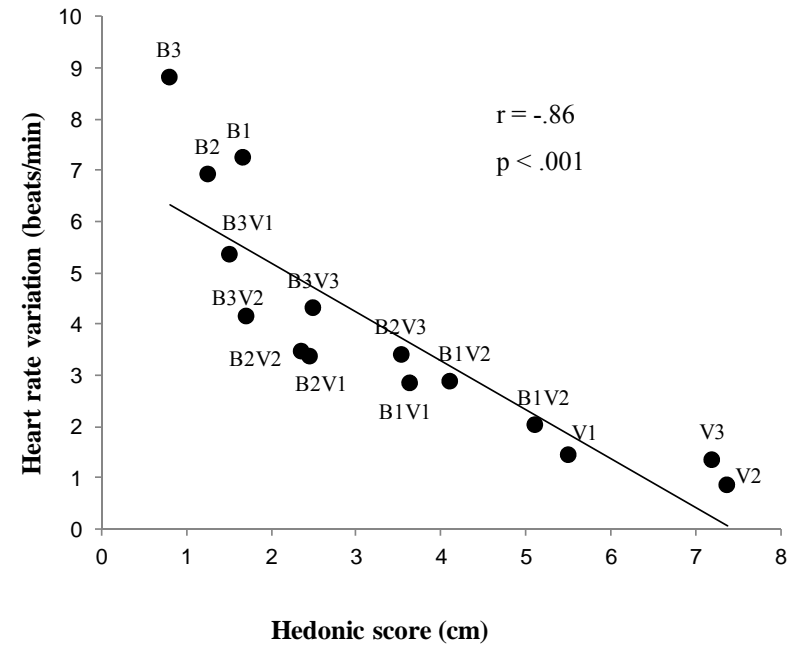

(a) Depressed subjects

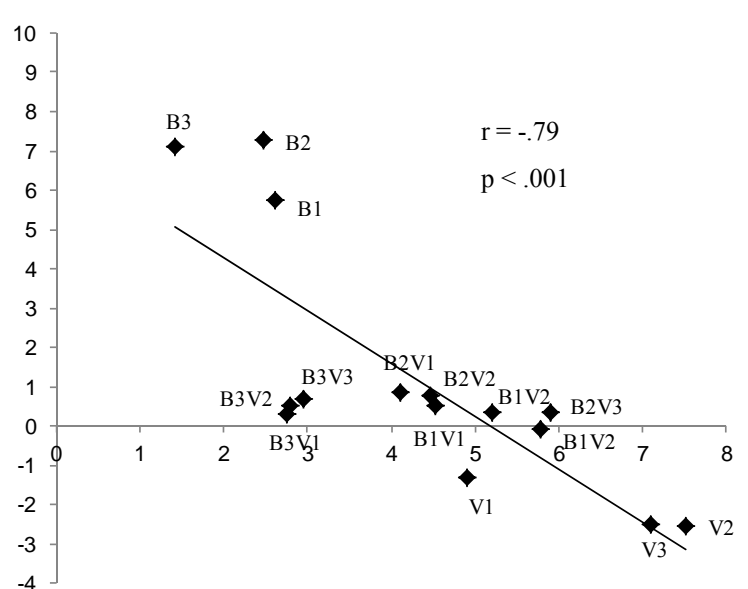

Hedonic score (cm)

(b) Healthy subjects

Figure 1.

Link between heart rate variation and hedonic self-evaluation of olfactory stimuli in both groups of subjects. Each point corresponds to an olfactory stimulus (V: vanillin; B: butyric acid). 
For the first objective, the results of the hedonic self-evaluation showed a significant difference between the two groups for two unpleasant unmixed stimuli (butyric acid) and for most of the binary mixtures (butyric acid/vanillin), which were perceived as significantly more unpleasant by the patients. No difference between groups was observed for pleasant stimuli. These last results for pleasant stimuli are in accordance with the literature (Pause et al., 2001; Thomas et al., 2002; Swiecicki et al., 2009; Clepce et al., 2010). However, for the cited above studies the calculation method of the subjects' pleasantness considers all the odors irrespective of the hedonic valence of the stimuli.

With regard to the objective HR measurement, the results revealed an increase in the HR responses of depressed patients compared to controls for almost all stimuli: two unpleasant olfactory stimuli, all pleasant olfactory stimuli, and all binary mixtures. Our observations in patients' group are in line with the results of Siegle et al. (2001) with subjects with the same diagnosis of major unipolar depression. More precisely, using pupillary dilation measures in the valence identification task, the authors showed that depressed patients displayed greater sustained processing (pupil dilation) in response to positive, negative and neutral stimuli (words) than non-depressed subjects. A similar phenomenon as in the present study was also observed in MDD individuals by Kaviani et al. (2004). The authors found that MDD subjects demonstrated anxiety levels (self-reported measure) associated with increased reactivity for both positive and negative valenced film clips. These observations suggest that the autonomic nervous system could be a reliable mirror of the emotional stimuli response in major unipolar depression. However, future studies measuring several other psychophysiological parameters of emotional stimulus response are needed to confirm this suggestion.

Previously, two research teams demonstrated that an increase in HR variation typically accompanies an unpleasant odorant inhaling experience (Alaoui-Ismaïli et al., 1997b; Bensafi et al., 2002a, 2002b). Our findings suggest that the implicit objective measures support the same negative "bias" as the subjective explicit responses. We could suppose that the presence of an olfactory cognitive bias observed in the depressed subjects could be related to the selective processing of negative information shown by these subjects, who are known for making dysfunctional attributions, and for engaging in more negative automatic thinking.

For all stimuli except the pleasant ones, the HR responses of the subjects in our study were consistent with their subjective ratings. One possible explanation of these divergent results is that the explicit hedonic rating may involve a higher decisional cognitive process, which may be impaired in depression. The objective perception of the positive odour as being less pleasant could also be due to anhedonia, a well-known symptom of depression which involves a gradual loss of the ability to experience physical and emotional pleasure. The neural representations of anhedonia and the hedonic evaluation of odours overlap significantly within a network consisting of the prefrontal and orbitofrontal cortex, the subcortical structures of the reward system and the limbic system, including the amygdala (Zatorre et al., 2000; Anderson et al., 2003; Keedwell et al., 2005; Gorwood, 2008). Abnormal activation in the amygdala and the orbitofrontal region has also been reported in depression (Drevets et al., 1992; Lesser et al., 1994). We can assume that the MDD patients' decreased hedonic response to the pleasant stimuli is connected to the theory of "positive attenuation", in other words, reduced reactivity to positive stimuli. Further research is needed to assess anhedonia in depressive patients (e.g. by using a self-rating scale; Chapman et al., 1976; Fawcett et al., 1983 ) in order to validate the hypothesis of a relationship between anhedonia and the decreased hedonic perception of pleasant stimuli revealed by the HR measures among depressed patients.

With regard to the second objective, our results indicated a significant relationship between the subjective explicit hedonic response and the objective HR response for both groups. Moreover, the hedonic and the HR variation scores for pleasant and unpleasant stimuli did not vary with the severity of depression. These observations are in line with recent results obtained by Sloan and Sandt (2010) in individuals with depression symptoms using pictures as emotional stimuli. The authors found no relationship between more severe symptoms of depression and blunted or heightened responses, as indicated by autonomic reactivity and self-report measures. Likewise, no correlation was found between severity of depression and the pleasantness rating of olfactory (Atanasova et al., 2010) and gustatory stimuli (Swiecicki et al., 2009).

No field data are available concerning any link between hedonic rating and HR variation responses in depression. Furthermore, the relationship between the subjective and objective responses of patients has previously been studied in the visual sensory modality; the objective measure involved analysing videotapes of the subjects' facial expressions recorded while they watched slides evoking different emotional responses (Berenbaum \& Oltmanns, 1992; Sloan et al., 1997). No significant relationship between the two types of measure was found for MDD patients in either of these studies. However, Sloan et al. (1997) pointed out that the slides depicting positive emotion may not have been sufficiently evocative because they did not elicit strong facial expressions in either depressive or control groups.

Some limitations of the present study merit discussion. First, only two odorants were used. Further research is needed to confirm our results and to extend the study of emotional responses to olfactory stimuli using several odours with contrasting hedonic valence.

Another limitation concerns smoking. The number of smokers is twice as high in patients as in controls. Smoking may reduce olfactory performance depending on the duration and dose (Frye et al., 1990). All the smokers in our study refrained from smoking for at least 30 - $40 \mathrm{~min}$ before the experiment, so there was no acute effect of smoking on the olfactory perception. However, a more chronic effect cannot be ruled out as we have no information about our subjects' smoking habits. Future research is required to investigate the potential effects of smoking on olfactory perception and hedonic processing in depression. Thirdly, we cannot rule out the possibility that our results were affected by specific medication. Nevertheless, previous studies on olfaction failed to find any effects of standard psychotropic medication (Martzke et al., 1997; Pause et al., 2001). At last, we can also hypothesize that our results could be due to the changes in of autonomic regulation of the heart in depression, such as activation of the sympathetic nervous system. Knowing that the results in this field were often inconclusive (Lehofer et al., 1997), this aspect must be check on in further studies aimed to replicate our observations. 


\section{Conclusion}

The present study has added knowledge concerning the olfactory hedonic perception in MDD. Using implicit instantaneous HR measures, findings revealed that depressed individuals were characterized by increased negative perception of olfactory stimuli whatever their hedonic valence. The results also suggest that there is a positive attenuation effect specific to pleasant olfactory stimuli. The results raise the question of whether the negative bias seen in depressed patients is a direct result of the clinical condition, or reflects permanent trait abnormality. To answer this question, two complementary measurements are required: one before psychiatric treatment, and one during a follow-up investigation a few months after remission. A close relationship between the explicit subjective hedonic response and the implicit instantaneous HR measure was also observed for both groups, suggesting that these two methods could be used for olfactory hedonic evaluation.

\section{REFERENCES}

Alaoui-Ismaïli, O., Robin, O., Rada, H., Dittmar, A., \& Vernet-Maury, E. (1997a). Basic emotions evoked by odorants: comparison between autonomic responses and self-evaluation. Physiology \& Behavior, 62, 713-720. doi:10.1016/S0031-9384(97)90016-0

Alaoui-Ismaïli, O., Vernet-Maury, E., Dittmar, A., Delhomme, G., \& Chanel, J. (1997b). Odor hedonics: Connection with emotional response estimated by autonomic parameters. Chemical Senses, 22, 237-248. doi:10.1093/chemse/22.3.237

American Psychiatric Association (1994). Diagnostic and statistical manual of mental disorder (4th ed.). Washington DC: American Psychiatric Association.

Anderson, A. K., Christoff, K., Stappen, I., Panitz, D., Ghahremani, D. G., Glover, G., Gabrieli, J. D. E., \& Sobel, N. (2003). Dissociated neural representations of intensity and valence in human olfaction. Nature Neuroscience, 6, 196-202. doi:10.1038/nn1001

Atanasova, B., El-Hage, W., Chabanet, C., Gaillard, P., Belzung, C., \& Camus, V. (2010). Olfactory anhedonia and negative olfactory alliesthesia in depressed patients. Psychiatry Research, 176, 190-196. doi:10.1016/j.psychres.2008.11.016

Bensafi, M., Rouby, C., Farget, V., Bertrand, B., Vigouroux, M., \& Holley, A. (2002a). Influence of affective and cognitive judgments on autonomic parameters during inhalation of pleasant and unpleasant odors in humans. Neuroscience Letters, 319, 162-166. doi:10.1016/S0304-3940(01)02572-1

Bensafi, M., Rouby, C., Farget, V., Bertrand, B., Vigouroux, M., \& Holley, A. (2002b). Autonomic nervous system responses to odours: The role of pleasantness and arousal. Chemical Senses, 27, 703-709. doi:10.1093/chemse/27.8.703

Bensafi, M., Rouby, C., Farget, V., Vigouroux, M., \& Holley, A. (2002). Asymmetry of pleasant vs unpleasant odor processing during affective judgment in humans. Neuroscience Letters, 328, 309-313. doi:10.1016/S0304-3940(02)00548-7

Berenbaum, H., \& Oltmanns, T. F. (1992). Emotional experience and expression in schizophrenia and depression. Journal of Abnormal Psychology, 101, 37-44. doi:10.1037/0021-843X.101.1.37

Bylsma, L. M., Morris, B. H., \& Rottenberg, J. (2008). A meta-analysis of emotional reactivity in major depressive disorder. Clinical Psychology Review, 28, 676-691. doi:10.1016/j.cpr.2007.10.001

Chapman, L. J., Chapman, J. P., \& Raulin, M. L. (1976). Scales for physical and social anhedonia. Journal of Abnormal Psychology, 85, 374-382. doi:10.1037/0021-843X.85.4.374

Clepce, M., Gossler, A., Reich, K., Kornhuber, J., \& Thuerauf, N. (2010). The relation between depression, anhedonia and olfactory hedonic estimates-A pilot study in major depression. Neuroscience Letters, 471, 139-143. doi:10.1016/j.neulet.2010.01.027

Cumming, A. G., Matthews, N. L., \& Park, S. (2011). Olfactory identification and preference in bipolar disorder and schizophrenia. Euro- pean Archives of Psychiatry and Clinical Neuroscience, 261, 251259. doi:10.1007/s00406-010-0145-7

Drevets, W. C., Videen, T. O., Price, J. L., Preskorn, S. H., Carmichael, S. T., \& Raichle, M. E. (1992). A functional anatomical study of unipolar depression. The Journal of Neuroscience: The Official Journal of the Society for Neuroscience, 12, 3628-3641.

Duburcq, A., Blin, P., Charpak, Y., Blachier, C., Allicar, M. P., Bouhassira, M., Hergueta, T., \& Lecrubier, Y. (1999). Use of a structured diagnostic interview to identify depressive episodes in an epidemicologic study: A posteriori internal validation. Revue d'épidémiologie et de santé publique, 47, 455-463.

Ehrlichman, H., \& Bastone, L. (1992). Olfaction and emotion. In M. Serby, \& K. L. Chobor (Eds.), Science of olfaction (pp. 410-438). Springer-Verlag, New York. doi:10.1007/978-1-4612-2836-3 15

Fawcett, J., Clark, D. C., Scheftner, W. A., \& Gibbons R. D. (1983). Assessing anhedonia in psychiatric patients. Archives of General Psychiatry, 40, 79-84. doi:10.1001/archpsyc.1983.01790010081010

Frye, R. E., Schwartz, B. S., \& Doty, R. L. (1990). Dose-related effects of cigarette smoking on olfactory function. The Journal of the American Medical Association, 263, 1233-1236. doi:10.1001/jama.263.9.1233

Gorwood, P. (2008). Neurobiological mechanisms of anhedonia. Dialogues in Clinical Neuroscience, 10, 291-299.

Kaviani, H., Gray, J., Checkley, S., Raven, P., Wilson, G., \& Kumari, V. (2004). Affective modulation of the startle response in depression: influence of the severity of depression, anhedonia, and anxiety. Journal of Affective Disorders, 83, 21-31. doi:10.1016/j.jad.2004.04.007

Keedwell, P. A., Andrew, C., Williams, S. C. R., Brammer, M. J., \& Phillips, M. L. (2005). The neural correlates of anhedonia in major depressive disorder. Biological Psychiatry, 58, 843-853. doi:10.1016/j.biopsych.2005.05.019

Lehofer, M., Moser, M., Hoehn-Saric, R., McLeod, D., Liebmann, P., Drnovsek, B., Egner, S., Hildebrandt, G., \& Zapotoczky H. G. (1997). Major depression and cardiac autonomic control. Biological Psychiatry, 42, 914-919. doi:10.1016/S0006-3223(96)00494-5

Lesser, I. M., Mena, I., Boone, K. B., Miller, B. L., Mehringer, C. M., \& Wohl, M. (1994). Reduction of cerebral blood flow in older depressed patients. Archives of General Psychiatry, 51, 677-686. doi:10.1001/archpsyc.1994.03950090009002

Lombion-Pouthier, S., Vandel, P., Nezelof, S., Haffen, E., \& Millot, J. L. (2006). Odor perception in patients with mood disorders. Journal of Affective Disorders, 90, 187-191. doi:10.1016/j.jad.2005.11.012

Martzke, J. S., Kopala, L. C., \& Good, K. P. (1997). Olfactory dysfunction in neuropsychiatric disorders: Review and methodological considerations. Biological Psychiatry, 42, 721-732. doi:10.1016/S0006-3223(96)00442-8

Montgomery, S. A., \& Asberg, M. (1979). A new depression scale designed to be sensitive to change. The British Journal of Psychiatry: The Journal of Mental Science, 134, 382-389. doi:10.1192/bjp.134.4.382

Moskowitz, H. R., Dravnieks, A., \& Klarman, L. A. (1976). Odor intensity and pleasantness for a diverse set of odorants. Perception \& Psychophysics, 19, 122-128. doi:10.3758/BF03204173

Pause, B. M., Raack, N., Sojka, B., Göder, R., Aldenhoff, J. B., \& Ferstl, R. (2003). Convergent and divergent effects of odors and emotions in depression. Psychophysiology, 40, 209-225. doi:10.1111/1469-8986.00023

Pause, B. M., Miranda, A., Göder, R., Aldenhoff, J. B., \& Ferstl, R. (2001). Reduced olfactory performance in patients with major depression. Journal of Psychiatric Research, 35, 271-277. doi:10.1016/S0022-3956(01)00029-2

Siegle, G., Granholm, E., Ingram, R. E., \& Matt, G. E. (2001). Pupillary and reaction time measures of sustained processing of negative information in depression. Biological Psychiatry, 49, 624-636. doi:10.1016/S0006-3223(00)01024-6

Sloan, D. M., Strauss, M. E., Quirk, S. W., \& Sajatovic, M. (1997). Subjective and expressive emotional responses in depression. Journal of Affective Disorders, 46, 135-141. doi:10.1016/S0165-0327(97)00097-9

Sloan, D. M., \& Sandt, A. R. (2010). Depressed mood and emotional 


\section{B. ATANASOVA ET AL.}

responding. Biological Psychology, 84, 368-374.

doi:10.1016/j.biopsycho.2010.04.004

Soussignan, R., Schaal, B., Marlier, L., \& Jiang, T. (1997). Facial and autonomic responses to biological and artificial olfactory stimuli in human neonates: Re-examining early hedonic discrimination of odors. Physiology \& Behavior, 62, 745-758.

doi:10.1016/S0031-9384(97)00187-X

Swiecicki, L., Zatorski, P., Bzinkowska, D., Sienkiewicz-Jarosz, H., Szyndler, J., \& Scinska, A. (2009). Gustatory and olfactory function in patients with unipolar and bipolar depression. Progress in NeuroPsychopharmacology and Biological Psychiatry, 33, 827-834. doi:10.1016/j.pnpbp.2009.03.030
Thomas, H. J., Fries, W., \& Distel, H. (2002). Evaluation of olfactory stimuli by depressed patients. Der Nervenarzt, 73, 71-77. doi:10.1007/s115-002-8150-9

Vernet-Maury, E., Alaoui-Ismaïli, O., Dittmar, A., Delhomme, G., \& Chanel, J. (1999). Basic emotions induced by odorants: A new approach based on autonomic pattern results. Journal of the Autonomic Nervous System, 75, 176-183. doi:10.1016/S0165-1838(98)00168-4

Zatorre, R. J., Jones-Gotman, M., \& Rouby, C. (2000). Neural mechanisms involved in odor pleasantness and intensity judgments. Neuroreport, 11, 2711-2716.

doi:10.1097/00001756-200008210-00021 